\title{
Suicide among people treated for drug use disorders: a Danish national record-linkage study
}

\author{
Morten Hesse " $^{*}$, Birgitte Thylstrup ${ }^{1}$, Abdu Kedir Seid ${ }^{1}$ and Jens Christoffer Skogen $2,3,4$
}

\begin{abstract}
Background: Substance use disorders are a major risk factor for suicide. However, less is known about specific risk factors for suicide in people with substance use disorders.

Methods: This population cohort study assessed suicide among people treated for drug use disorders in Denmark 2000-2010, and described risk factors for completed suicide. Data from 27,942 individuals enrolled in treatment were linked to national registers and matched with controls without drug use disorder and with $(n=138,136)$ or without psychiatric history $(n=1574)$. Competing risk regression was used to identify risk factors of completed suicide.
\end{abstract}

Results: There were 163 suicides among patients with a history of drug treatment ( $0.6 \%$ of patients). Increased risk was associated with younger age at enrolment (hazard ratio $[H R]=0.97,95 \%$ confidence interval $(\mathrm{Cl}): 0.95,0.98)$, history of psychiatric care $(\mathrm{HR}=1.96, \mathrm{Cl} 95 \%$ : $1.39,2.77)$, opioid use $(\mathrm{HR}=1.81,95 \% \mathrm{Cl}: 1.23$, 2.68), and alcohol use $(H R=1.56,95 \% \mathrm{Cl}: 1.09,2.23)$. Lower risk was associated with cannabis use (HR=0.69, $95 \%$ Cl: $0.50,0.96)$. Compared with age- and gender-matched controls without a history of treatment for substance use disorders or recent psychiatric care, the standardized mortality ratio due to suicide was 7.13 for people with drug use disorder without a history of psychiatric care (95\% Cl: 5.81, 8.44), 13.48 for people with drug use disorder and psychiatric history (95\% Cl: 9.75, 17.22), and 13.61 for people with psychiatric history only (95\% Cl: 6.72, 20.50).

Conclusions: Risk of suicide is increased among people with drug use disorders. Access to treatment for comorbid mental health problems for people with drug use disorders could potentially reduce risk of suicide.

Keywords: Drug use disorder, Suicidal behaviour, Mental health, Treatment, Longitudinal study, Cohort, Competing risks

\section{Background}

Suicide is a global phenomenon; nearly 800,000 people die from suicide every year, with a higher prevalence among men compared to women, peaking between the age of 15 and 24 among women, and between the age of 25 and 45 among men [1]. According to the 2016 Global Burden of Disease Study, suicide was among the top ten leading causes of death in Western European countries [2].
Several meta-analytic studies have reported an association between substance use, including alcohol and illicit drug use on the one hand, and suicidal ideation, suicide attempts, and suicide death on the other $[3,4]$. A recent meta-analysis found that in case-control psychological autopsy studies, the presence of a drug use disorder (DUD) was associated with a 7-fold increase in suicide [5]. Further, previous studies have reported significant associations between the misuse of prescription drugs and suicidal ideation or suicide $[6,7]$.

\footnotetext{
* Correspondence: mh.crf@psy.au.dk

${ }^{1}$ Center for Alcohol and Drug Research, Aarhus University, Aarhus, Denmark

Full list of author information is available at the end of the article
}

(c) The Author(s). 2020 Open Access This article is distributed under the terms of the Creative Commons Attribution 4.0 International License (http://creativecommons.org/licenses/by/4.0/), which permits unrestricted use, distribution, and 


\section{Risk factors related to suicide}

Significant risk factors for suicidal behavior include misuse of alcohol or drugs, a history of self-harm and attempted suicide, and psychiatric disorders [8-13]. Globally, alcohol dependence (13.3\%), amphetamine dependence $(2.4 \%)$, opioid dependence $(1.9 \%)$ and cocaine dependence $(0.9 \%)$ are important attributable factors for suicide [14]. In Denmark, alcohol use was attributable to $33.3 \%$ of deaths due to suicide in 2017 , while $3.1 \%$ were attributable to drug use according to global burden of disease estimates [15]. Cannabis use and cannabis use disorders have been shown to be correlated with suicidal behaviour and ideation, although there is no convincing evidence that the link is causal [16]. It is likely that the strong association between cannabis and suicide could be explained by other factors, such as co-morbid mental health and behavioural problems [17].

Previous research shows that mood and anxiety disorders are risk factors of suicide [18], including both unipolar and bipolar mood disorders [19], especially in the early phases of illness [20]. In addition, borderline personality disorder is associated with an elevated risk of completed suicide, especially among individuals with multiple hospitalizations [21].

Despite the large body of research on suicide and substance use and psychiatric co-morbidity, relatively few studies have assessed predictors of suicide in people with psychoactive DUD. A recent study found that both selfreported psychiatric symptoms and psychiatric treatment history independently predicted completed suicide among people with DUD [22]. However, beyond this single study, there is a paucity of research that has examined risk factors associated with suicide completion in individuals with DUD.

The present study had two aims: [1] to assess excess mortality due to suicide among people treated for DUD in Denmark, and [2] to describe socio-demographic and clinical risk factors associated with completed suicide.

\section{Methods}

Data

The present study used data from multiple Danish national registers, all of which are continuously updated.

The Civil Registration System was established in 1968 and includes unique individual identification number, name, gender, date of birth, place of birth and residence, citizenship, identity of parents and spouses [23].

The Registry of Drug Abusers in Treatment has been recording information on people seeking treatment for DUD in publically funded treatment centers under the Danish social services since 1996 [24].

The National Patient Register was established in 1977 and contains personal and admission data for secondary care. The personal data include the unique identification number, municipality, and region of residence. The admission data include hospital and department codes, admission type, patient contact type (inpatient, outpatient, or emergency department), referral information, contact reason, and dates of admission and discharge [25].

The Psychiatric Central Research Register has recorded episodes of psychiatric care since 1970, and contains information for all outpatient, inpatient, and emergency contacts at psychiatric hospitals, including dates of beginning and end of treatment, diagnoses, type of referral, place of treatment, place of residence, and mode of admission [26].

The Danish Registry for Causes of Death contains information on dates and causes of death based up on the death certificate. Since 1875, the Danish National Board of Health has maintained the registers covering deaths among all Danish residents dying in Denmark, and since 1970 such records have been computerized [27].

The Central Criminal Register contains information about offenses and offenders in criminal cases for use in criminal procedures since November 1978. Information is transferred from the central crime register to Statistics Denmark [28].

All registers were linked, using the unique identification number assigned to each individual up on birth or first entry to Denmark as an immigrant.

The data for this study are stored on secure servers at Statistics Denmark, and all procedures were approved by the Danish Data Protection Agency. Since the data used for this study were collected and stored for monitoring and quality assurance, no ethics evaluation was needed under Danish law.

\section{Inclusion criteria}

Patients were included in the study if they had been enrolled in a publicly funded outpatient treatment facility for DUD in Denmark between 2000 and 2010, and were in the age range of 18 to 75 years at time of admission. Patients were excluded if their date of death was invalid. Less than five cases were omitted from the analyses, as their date of death was recorded as January 1st 1960, although they had been in treatment after January 1st 2000 (the exact number cannot be given due to data protection rules prohibiting the download of microdata). We followed the patients over the entire observation period, beginning from first registered treatment enrolment to completed suicide or December 31, 2010, whichever occurred first.

\section{Measures}

\section{Outcome variable}

The outcome in the study was defined as time from the first registered enrollment at a treatment center for 
DUD to completed suicide. Dates and causes of death were identified using the Danish Register of Cause of Death. We used ICD-10 codes to identify all completed suicides ascribed to intentional self-harm (X60-X84) or the sequelae of intentional self-harm (Y87.0) [29].

\section{Predictors}

The information on all substances used by the patients in the twelve months prior to enrolment in treatment were extracted from The Registry of Drug Abusers Undergoing Treatment. These variables were dummy-coded for the following types of substances: any opioids; central stimulants; cannabis; any recorded problem drinking in the database; use of benzodiazepines; methylenedioxymethamphetamine; and intravenous drug use. Further, we used a categorical predictor indicating previous drug treatment versus no previous drug treatment, or missing information on previous treatment based on the admission form. Using the code of reason for contact from the $\mathrm{Na}$ tional Patient Register, we constructed a dummy variable representing any record of admission to a hospital in Denmark due to self-harm within the past 12 months leading up to the first registered admission to drug use disorder treatment. Using the Central Criminal Register, a dummy variable was created to indicate whether a person had been charged with a crime within the past 12 months, leading up to the first registered treatment admission. The sociodemographic variables include gender, age, civil status (living without a partner or not), not being in education, employment or training, and immigrant status (born in Denmark or not).

\section{Analyses}

Descriptive statistics are reported as percentages for dichotomous variables and means with standard deviations for all other variables. Comparison between groups was done using Nelson-Aalen curves of the cumulative hazard and estimated cumulative incidence functions. Time-to-event analysis for completed suicide was conducted using Fine and Gray's competing risks analysis [30], in which the cumulative incidence function (CIF); i.e., $\mathrm{C}_{\mathrm{e}}(\mathrm{t})$ gives the proportion of patients at time $t$ who have experienced event $e$, while accounting for the fact that patients can experience another event that prevents event $e$ from happening, labeled the competing event or competing risk (e.g., death not caused to suicide will rule out later death caused by suicide).

In the analyses, subjects were considered to have experienced the event if they died due to suicide, to have experienced the competing event, if they died from any other cause, and to be censored if no event took place by December 31st, 2010.
All $p$-values were 2 -tailed, and level of significance was assessed as a Type I error with rate of alpha 0.05. All statistical analyses were performed using Stata 15 [31].

In order to compare the rate of suicide among people treated for DUD with the rate in the total population, we drew matched controls from a representative sample of the national population without a history of public funded treatment for DUD or alcohol use disorders. The sample size of the control group is five randomly drawn individuals from the total population $(n=139,710)$, proportionate to each individual enrolled at a DUD treatment center within the time period of this study, using similar gender and age group at enrolment date at the treatment centers. The age groups were $18-27,28-37$, $38-47$, and $48-75$ years at the time of admission to treatment.

A random enrolment date was generated for the control group. The only restriction made in the matching was that the individuals in the control group did not die before the enrolment date, the year that the follow-up started, and did not have a record of treatment for a drug or alcohol use disorder in the databases. In the control group, the time-to-event outcome variable was created after generating a random enrolment date with a beta distribution.

We analyzed the standardized mortality ratios (SMRs) to estimate the suicide gap between individuals with DUD, recent psychiatric history, or both, compared with a general population sample with neither. Comparisons were made using three categories: individuals in the control group who had past year psychiatric care history, patients treated for DUD with past year psychiatric care, and patients treated for DUD without past year psychiatric care. We used individuals in the control group without past year psychiatric care as the reference group.

\section{Results \\ Descriptive statistics}

A cohort of 27,942 patients enrolled in treatment for DUD between 2000 and 2010 were identified in the study sample (see Fig. 1). Table 1 shows baseline demographic and clinical characteristics of individuals in the study. The most commonly registered drugs were cannabis 14,651 (52.4\%), opioids 11,131 (39.8\%), and central stimulants 8661 (31.0\%). The majority of patients were men $21,171(75.8 \%)$, and the mean age was 33.5 (standard deviation $[\mathrm{SD}]=10.5$ ). Most of the patients were not in education, employment or training 19,276 (69.0\%), were living without a partner 20,204 (72.3\%), and had not been treated for DUD previously 15,212 (54.4\%).

In the sample of people treated for DUD, $163(0.6 \%)$ patients had completed suicide, of which $52.1 \%$ had used violent methods, and $47.9 \%$ had died from poisonings. 


\section{Admitted for treatment $(n=33,217)$}

Excluded due to outside age range at admission $(n=5,275)$

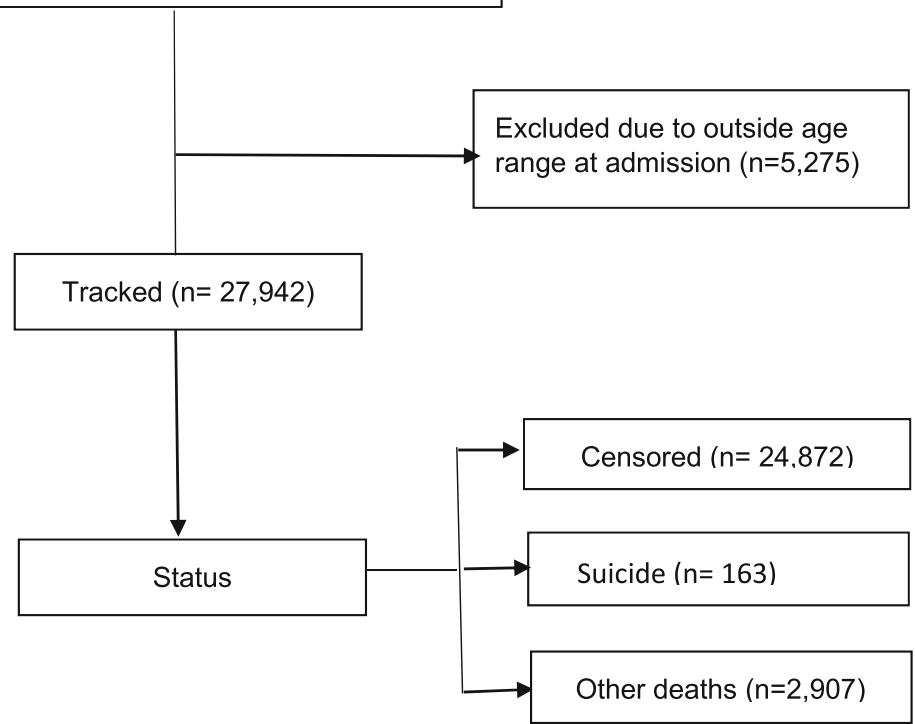

Fig. 1 Flow of participants through the study

Table 1 Sample Characteristics and Results of Risk Factors Associated With Completed Suicide Among People Treated for Drug Use Disorders Between 2000 and $2010(n=27,942)$

\begin{tabular}{|c|c|c|}
\hline & $n /$ percentage (mean/standard deviation) & Sub hazard ratio ( $95 \%$ confidence interval) \\
\hline \multicolumn{3}{|l|}{ Year before drug use disorder treatment variables $^{1}$} \\
\hline Criminal charges within the past year & $11,663(41.7)$ & $0.86(0.62,1.20)$ \\
\hline Self-harm within the past year & $631(2.3)$ & $1.48(0.70,3.10)$ \\
\hline Psychiatric care within the past year & $5298(19.0)$ & $1.96(1.39,2.77)$ \\
\hline \multicolumn{3}{|l|}{ Clinical variables ${ }^{2}$} \\
\hline Use of opioids & $11,131(39.8)$ & $1.81(1.23,2.68)$ \\
\hline Use of central stimulants & $8661(31.0)$ & $0.85(0.58,1.25)$ \\
\hline Use of cannabis & $14,651(52.4)$ & $0.69(0.50,0.96)$ \\
\hline Use of Methylenedioxymethamphetamine & $2023(7.2)$ & $0.71(0.34,1.46)$ \\
\hline Alcohol use (problem drinking) & $7182(25.7)$ & $1.56(1.09,2.23)$ \\
\hline Use of benzodiazepines & $4458(16.0)$ & $1.18(0.79,1.76)$ \\
\hline Intravenous drug use & $15,299(54.8)$ & $1.23(0.86,1.78)$ \\
\hline \multicolumn{3}{|l|}{ Treatment status $^{2}$} \\
\hline Previously treated & $9623(34.5)$ & Reference \\
\hline Never treated & $15,212(54.4)$ & $1.14(0.78,1.67)$ \\
\hline Missing information & $3107(11.1)$ & $1.44(0.84,2.45)$ \\
\hline \multicolumn{3}{|l|}{ Socio-demographics ${ }^{1}$} \\
\hline Female gender & $6771(24.2)$ & $0.71(0.47,1.05)$ \\
\hline Age (mean/standard deviation) & $27,942(33.5 / 10.5)$ & $0.97(0.95,0.98)$ \\
\hline Not in education, employment or training & $19,276(69.0)$ & $1.13(0.76,1.70)$ \\
\hline Living without partner & $20,204(72.3)$ & $1.10(0.75,1.63)$ \\
\hline Immigrant $^{a}$ & $2286(8.2)$ & $0.78(0.41,1.47)$ \\
\hline
\end{tabular}

Note: ${ }^{a}$ not born in Denmark

${ }^{1}$ Based on record linkage

${ }^{2}$ Based on the Registry of Drug Abusers in Treatment 
In addition, 2907 (10.4\%) died due to other causes. Among the controls across both people with and without recent psychiatric history, 111 (0.1\%) had completed suicide, of which $85.6 \%$ had used violent methods and $14.4 \%$ had died from poisonings. Further, 1607 (1.2\%) died from other causes.

In the case sample, 50 (31.0\%) of suicide completers had received psychiatric care in the past year compared to $15(13.5 \%)$ in the control group. The prevalence of psychiatric care among those who did not commit suicide were 1461 (1.1\%) in the control group versus 4619 (18.6\%) in patients treated for DUD.

Figure 2 shows the Nelson-Aalen cumulative incidence of suicide for all four groups (i.e., [1] people with a history of treatment for DUD without psychiatric history, [2] people with a history of treatment for DUD with psychiatric history, [3] people with no history of treatment for alcohol or DUD without psychiatric history, and [4] people with no history of treatment for alcohol or DUD with psychiatric history.

The Nelson-Aalen estimator plot shows that the risk of dying by suicide differs between the case and control groups, as well as across past year psychiatric care status, where cases with past year psychiatric care had the highest risk of dying from suicide and the controls with no past psychiatric care had the lowest risk.

\section{Competing-risks regression analysis for risk of suicide among people treated for DUD}

The mean time at risk for completed suicide was 5.8 years. The results from the competing-risks regression model (Table 1) shows that the risk of completed suicide was higher among those who were in psychiatric care in the year prior to treatment for DUD $(\mathrm{HR}=1.96,95 \% \mathrm{CI}: 1.39,2.77)$. The two substancerelated risk factors associated with higher risk of completed suicide were opioid use $(\mathrm{HR}=1.81,95 \%$ CI: $1.23,2.68)$ and alcohol $(\mathrm{HR}=1.56,95 \% \mathrm{CI}: 1.09$, $2.23)$, whereas use of cannabis was associated with lower risk of completed suicide $(\mathrm{HR}=0.69,95 \% \mathrm{CI}$ : $0.50,0.96)$. Among the socio-demographic variables, older age $(\mathrm{HR}=0.97,95 \% \mathrm{CI}: 0.95,0.98)$ was associated with lower risk of suicide. Figure 3 shows the adjusted cumulative incidence function by psychiatric care history based on the competing risks regression.

\section{Comparison to general population sample with and without psychiatric history}

Comparisons between groups are shown in Table 2.

In the following comparisons, we shall refer to ageand gender-matched controls without psychiatric history as the "reference group". Patients treated for DUD without past year psychiatric care history were more likely to commit suicide than the reference group $(\mathrm{SMR}=7.13$, 95\% CI: 5.81, 8.44). Thus, the risk for suicide among people with a history of DUD and no psychiatric history was 7.13 times higher compared with a person in the general population with no recent history of psychiatric care. The suicide SMR for individuals with DUD and recent psychiatric history was 13.48 (95\% CI: 9.75, 17.22).

Finally, individuals taken from the general population with a history of psychiatric care in the last 365 days before their random enrolment date were more likely to commit suicide $(\mathrm{SMR}=13.61,95 \% \mathrm{CI}: 6.72,20.50)$ than the reference group.

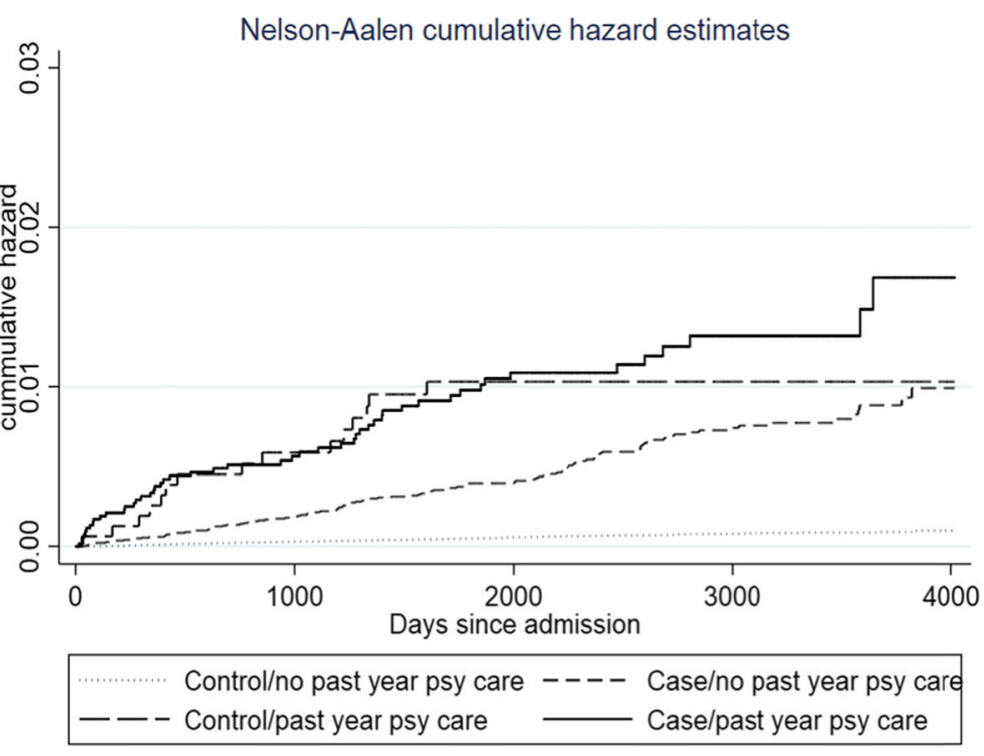

Fig. 2 Nelson-Aalen curves for completed suicide between control and case groups with or without past year psychiatric care 


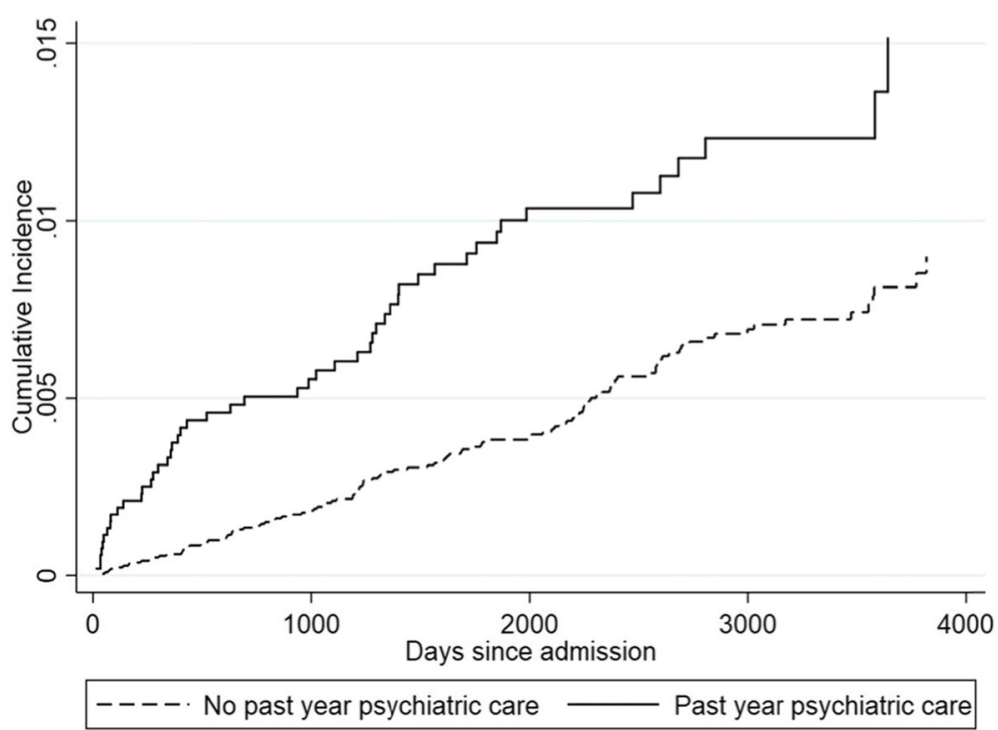

Fig. 3 Comparative cumulative incidence of completed suicide with and without past year psychiatric care for individuals with DUD

\section{Discussion}

\section{Summary of findings}

Using multiple Danish national registers, we examined whether excess mortality due to suicide exists among people treated for DUD, and identified risk factors associated with completed suicide between 2000 and 2010. We also compared the prevalence of suicide between individuals treated for DUD and the general population.

Patients who had been in treatment for DUD, but who did not seek psychiatric care in the past year had more than a sevenfold increase in risk of suicide after admission to treatment, in comparison to ageand gender matched individuals from the general population without a history of recent psychiatric care. This is a substantial increase in risk, which is in line with findings from psychological autopsies [5], and the $95 \%$ confidence interval between five and eight clearly indicates a statistically significant difference.

Patients who had been in treatment for a DUD with past psychiatric care had a more than 13 times higher risk of committing suicide compared with gender or age-matched individuals with no history of treatment for substance use disorders and psychiatric care in the general population. However, the high relative elevation must be considered in light of the low base-rate of completed suicide, and it must be remembered that among the individuals that we tracked for up to ten years, less than $1 \%$ took their own lives (compare also [32]).

In addition, it should be noted that people from the general population with a recent history of psychiatric care had practically the same elevation in risk as patients with both a history of treatment for DUD and recent psychiatric care $(\mathrm{SMR}=13.6)$.

Our findings highlight some key risk factors for suicide among people seeking treatment for DUD. We found that younger age, past year history of psychiatric care, use of opioids, and use of alcohol were all associated with increased risk of suicide. Use of cannabis was associated with a lower risk of suicide. Past psychiatric care was associated with a higher risk of suicide in our cohort. As would be expected, mental health problems were associated with an elevated suicide risk in both the DUD cohort and among the controls, a finding also reported by Cavanagh et al. [33].

Table 2 Standardized Mortality ratios due to suicide (SMR) of Cases and Controls With and Without Past Year Psychiatric Care

\begin{tabular}{lllll}
\hline & $\begin{array}{l}\text { Control without past psychiatric care } \\
(n=138,136)\end{array}$ & $\begin{array}{l}\text { Control with past psychiatric } \\
\text { care }(n=1574)\end{array}$ & $\begin{array}{l}\text { Case with past psychiatric } \\
\text { care }(n=5298)\end{array}$ & $\begin{array}{l}\text { Case without past psychiatric care } \\
(n=22,644)\end{array}$ \\
& $\operatorname{SMR}(95 \% \mathrm{Cl})$ & $\mathrm{SMR}(95 \% \mathrm{Cl})$ & $\mathrm{SMR}(95 \% \mathrm{Cl})$ & $\mathrm{SMR}(95 \% \mathrm{Cl})$ \\
\hline Men & (ref) & $12.40(5.08-19.74)$ & $12.70(8.60-16.79)$ & $6.63(5.28-7.98)$ \\
Women & (ref) & $42.92(0.86-84.98)$ & $39.27(17.92-60.63)$ & $19.55(10.98-28.11)$ \\
All & (ref) & $13.61(6.72-20.50)$ & $13.48(9.75-17.22)$ & $7.13(5.81-8.44)$ \\
\hline
\end{tabular}

Cases: Patients Treated for Drug Use Disorder 
Our finding that opioid use was a strong predictor of completed suicide is consistent with other studies [7, 34, 35], even if those other studies have assessed suicidal ideation and attempts, rather than completed suicide. In our context, opioid use was part of a drug problem that had led to treatment, meaning that our findings may not be relevant for opioid use among pain patients (compare [36]).

Our finding that alcohol use was a strong predictor of completed suicide is also consistent with other studies $[37,38]$. For instance, one in five people who committed suicide in an Australian psychological autopsy study were found to have an alcohol use disorder [39]. In addition, alcohol intoxication is associated with methods of increased lethality when attempting suicide, i.e. methods that have a higher risk of a fatal outcome [40]. However, this study adds to the literature by showing that even among people with other DUD, alcohol is an independent contributor to suicide risk.

Our finding that cannabis was associated with lower risk of completed suicide was unexpected [41, 42]. It is possible that third variable confounding underlie these negative correlations. However, some research suggests at least one active component in cannabis, namely cannabidiol [43], can have beneficial effects on substance use disorders, by reducing drug seeking behaviour and symptoms of anxiety [43]. This may in turn reduce the risk of completed suicide in the context of multiple types of DUD. It is also possible that the general loss of initiative associated with cannabis use may indirectly influence suicidal behaviour as well [44].

Our findings of no association between self-harm and completed suicide is contrary to other studies (see 12). It is possible that we did not capture self-harm with sufficient precision, or that our patient group did not present with self-harm at hospital-based clinics, including emergency departments, but rather with symptoms of intoxication or withdrawal.

\section{Implications for practice}

There is growing evidence that patients with DUD who experience mental health problems may be helped by interventions that are integrated with substance abuse treatment. At least one meta-analysis [45], as well as more recent clinical trials [46-48], indicate that both mental health problems and substance use disorders are receptive to psychotherapy as a mode of treatment. Evidence from large-scale trials indicate that integrated services for people with co-morbid substance use disorders and mental health problems can be implemented in routine clinical settings [49].

Furthermore, there is evidence that antidepressants can be helpful for people with co-morbid depression and substance use disorders, even if the effects are larger when patients are abstinent before being treated $[50,51]$ and the quality of the evidence is mixed [52]. In this context, benefits and risks should be carefully weighted: There is a risk that antidepressants may become part of a lethal cocktail of substances leading to a fatal overdose [53]. However, this relationship is complicated, as depression and anxiety disorders may themselves be associated with overdose risk, and this risk may be attenuated by treatment with antidepressants that is continuous over a longer period of time [54].

Finally, other studies show that mental health problems can be validly assessed among people undergoing treatment for DUD with use of self-report instruments [55-57]. As such, identification of co-existing psychopathology should be highlighted even more as a potential first step towards suicide prevention.

\section{Strengths and limitations}

Some limitations must be noted for this study. First, as with any register-based study, we were not able to provide direct quality control over the process of data collection. Secondly, and perhaps more importantly, suicides by poisonings may be difficult to discriminate from overdoses [58]. This could especially lead to an under-estimation of the association between opioid use and suicide, as opioids are the drugs that are primarily involved in accidental poisonings [58].

In the present study, the case definition of suicide only included ICD-10 causes of death codes for intentional self-inflicted poisoning or injury (X60$\mathrm{X} 84$ ), and sequelae of self-harm (Y87.0). A systematic review from 2012 concluded that suicide deaths are generally under-reported [59]. In this review, the level of under-reporting varied between different primary studies, but high quality studies tended to report less under-reporting than studies of poorer quality. As such, it is likely that our case definition leads to lower bound estimates of suicide deaths and may dilute estimated associations. A potential solution to under-reporting is redistribution of ICD-10 death codes which may contain suicide deaths (such as undetermined intent injury codes (Y10-Y34), and exposure to undetermined factors (X59) [2]). However, a recent Norwegian national registry study covering death certificates for the years 2005-2014 reported that redistribution of X59 codes which constituted $26 \%$ of all injury deaths, only changed the suicide estimates by 2 percentage points (60). In the same study, $12 \%$ of all injury deaths were assigned undetermined intent injury codes (Y10-Y34). The Norwegian and Danish registries of Causes of Death share many similarities, use the same coding system (ICD-10), and are both of high quality. It is therefore unlikely that redistribution of death codes would change our 
overall findings to a great extent, perhaps with exception of actual intentional over-doses being assigned as undetermined intent (Y10-Y15). Finally, while it was a strength to include a matched control group in this study, because it allowed us to compare the prevalence of suicide between individuals who attended DUD treatment and individuals who did not, we cannot exclude the possibility of selection bias due to the chosen matching strategy.

\section{Conclusions}

Risk of suicide is increased among people with drug use disorders compared with the general population, although the number of suicides among people with drug use disorder is relatively small compared with drugrelated deaths. The main risk factors for suicide in patients with drug use disorders are a history of mental health problems, and opioid and alcohol use.

\section{Abbreviations}

Cl: Confidence interval; DUD: Drug use disorder; HR: Hazard ratio; ICD-

10: International classification of Diseases, Tenth Revision; SMR: Standardized mortality ratios due to suicide

\section{Acknowledgements}

We wish to acknowledge the work of Mads Uffe Pedersen, Kirsten Søndergaard Frederiksen, and Michael Mulbjerg Pedersen in developing the register-based research program of which this study is a part.

\section{Authors' contributions}

$\mathrm{MH}, \mathrm{AK}$, and $\mathrm{BT}$ designed the study. $\mathrm{MH}$ and $\mathrm{BT}$ directed its implementation, including quality assurance and control. $\mathrm{MH}, \mathrm{AK}$, and BT designed the study's analytic strategy and conducted the literature review. JCS helped conduct the analytic strategy, literature review, and the discussion. All authors contributed significantly to writing the manuscript, and all authors have read and approved the final version.

\section{Funding}

This study was funded under an umbrella funding for the Center for Alcohol and Drug Research, provided by the Danish Parliament through the budget law. The funder had no say in the decision to analyze, publish, or interpret the data.

\section{Availability of data and materials}

The datasets analyzed for the present study are the property of the Danish government, and are stored on servers owned by Statistics Denmark. The Danish Board of Health data (https://sundhedsdatastyrelsen.dk/da), and Statistics Denmark (https://www.dst.dk/da/) can provide information about how to apply for access.

\section{Ethics approval and consent to participate}

All data used for this study were collected for quality assurance or monitoring purposes, and under Danish legislation, no ethics approval or consent to participate was necessary.

\section{Consent for publication}

Not applicable.

\section{Competing interests}

All authors declare that they have no competing interests.

\section{Author details}

${ }^{1}$ Center for Alcohol and Drug Research, Aarhus University, Aarhus, Denmark. ${ }^{2}$ Department of Health Promotion, Norwegian Institute of Public Health, Bergen, Norway. ${ }^{3}$ Alcohol \& Drug Research Western Norway, Stavanger
University Hospital, Stavanger, Norway. ${ }^{4}$ Department of Public Health, Faculty of Health Sciences, University of Stavanger, Stavanger, Norway.

Received: 5 August 2019 Accepted: 22 January 2020

Published online: 31 January 2020

\section{References}

1. World Health Organization. Monitoring health for the SDGs, sustainable development goals. Geneva: World Health Organization; 2018.

2. Naghavi M, Collab GBDS-H. Global, regional, and national burden of suicide mortality 1990 to 2016: systematic analysis for the global burden of disease study 2016. BMJ. 2019;364:194.

3. Breet E, Goldstone D, Bantjes J. Substance use and suicidal ideation and behaviour in low- and middle-income countries: a systematic review. BMC Public Health. 2018;18(1):549.

4. Poorolajal J, Haghtalab T, Farhadi M, Darvishi N. Substance use disorder and risk of suicidal ideation, suicide attempt and suicide death: a meta-analysis. Public Health (Oxf). 2016;38(3):e282-e91.

5. Conner KR, Bridge JA, Davidson DJ, Pilcher C, Brent DA. Metaanalysis of mood and substance use disorders in proximal risk for suicide deaths. Suicide Life Threat Behav. 2019;49(1):278-92.

6. Borgschulte M, Corredor-Waldron A, Marshall G. A path out: prescription drug abuse, treatment, and suicide. J Econ Behav Organ. 2018;149:169-84.

7. Ashrafioun L, Bishop TM, Conner KR, Pigeon WR. Frequency of prescription opioid misuse and suicidal ideation, planning, and attempts. J Psychiatr Res. 2017:92:1-7.

8. Halladay JE, Boyle MH, Munn C, Jack SM, Georgiades K. Sex differences in the association between Cannabis use and suicidal ideation and attempts, depression, and psychological distress among Canadians. Can J Psychiatry. 2018:64(5):345-50.

9. Halladay JE, Munn C, Boyle M, Jack SM, Georgiades K. Temporal changes in the cross-sectional associations between Cannabis use, suicidal ideation, and depression in a nationally representative sample of Canadian adults in 2012 compared to 2002. Can J Psychiatry. 2019:706743719854071.

10. Shalit N, Shoval G, Shlosberg D, Feingold D, Lev-Ran S. The association between cannabis use and suicidality among men and women: a population-based longitudinal study. J Affect Disord. 2016;205:216-24.

11. Beautrais AL, Joyce PR, Mulder RT. Cannabis abuse and serious suicide attempts. Addiction. 1999;94(8):1155-64.

12. Hawton K, van Heeringen K. Suicide. Lancet. 2009;373(9672):1372-81.

13. Chan MK, Bhatti H, Meader N, Stockton S, Evans J, O'Connor RC, et al. Predicting suicide following self-harm: systematic review of risk factors and risk scales. Br J Psychiatry. 2016;209(4):277-83.

14. Ferrari AJ, Norman RE, Freedman G, Baxter AJ, Pirkis JE, Harris MG, et al. The Burden Attributable to Mental and Substance Use Disorders as Risk Factors for Suicide: Findings from the Global Burden of Disease Study 2010. PloS One. 2014;9(4):e91936.

15. Global Burden of Disease Study. Global Burden of Disease Study 2017 (GBD 2017) Results. Seattle, United States: Institute for Health Metrics and Evaluation (IHME); 2017.

16. Borges $\mathrm{G}$, Bagge $\mathrm{CL}$, Orozco R. A literature review and meta-analyses of cannabis use and suicidality. J Affect Disord. 2016;195:63-74.

17. Price C, Hemmingsson T, Lewis G, Zammit S, Allebeck P. Cannabis and suicide: longitudinal study. Br J Psychiatry. 2009;195(6):492-7.

18. Racine M. Chronic pain and suicide risk: a comprehensive review. Prog Neuro-Psychopharmacol Biol Psychiatry. 2018;87:269-80.

19. Holma KM, Haukka J, Suominen K, Valtonen HM, Mantere O, Melartin TK et al. Differences in incidence of suicide attempts between bipolar I and II disorders and major depressive disorder. Bipolar Disord. 2014;16(6):652-61.

20. Angst F, Stassen HH, Clayton PJ, Angst J. Mortality of patients with mood disorders: follow-up over 34-38 years. J Affect Disorders. 2002; 68(2-3):167-81.

21. Temes CM, Frankenburg FR, Fitzmaurice GM, Zanarini MC. Deaths by Suicide and Other Causes Among Patients With Borderline Personality Disorder and Personality-Disordered Comparison Subjects Over 24 Years of Prospective Follow-Up. J Clin Psychiatry. 2019;80(1). https://doi.org/10.4088/JCP. $18 \mathrm{~m} 12436$.

22. Thylstrup B, Bloomfield K, Hesse M. Incremental predictive validity of the addiction severity index psychiatric composite score in a consecutive cohort of patients in residential treatment for drug use disorders. Addict Behav. 2018;76(1):201-7. 
23. Pedersen CB. The Danish civil registration system. Scand J Public Health. 2011;39(7 Suppl):22-5.

24. Ministry of Children and Social Affairs. Bekendtgørelse om dataindberetninger på socialområdet [Executive Order on Data Reporting on Social Services]: retsinformation.dk; 2018 [Available from: https://doi.org/ https://www.retsinformation.dk/pdfPrint.aspx?id=196791.

25. Schmidt M, Schmidt SAJ, Sandegaard JL, Ehrenstein V, Pedersen L, Sørensen HT. The Danish National Patient Registry: a review of content, data quality, and research potential. Clin Epidemiol. 2015;7:449-90.

26. Mors O, Perto GP, Mortensen PB. The Danish psychiatric central research register. Scand J Public Health. 2011;39:54-7.

27. Helweg-Larsen K. The Danish register of causes of death. Scand J Public Health. 2011;39:26-9.

28. Lund J. Mentally retarded criminal offenders in Denmark. Br J Psychiatry. 1990;156:726-31.

29. WHO. ICD-10 : international statistical classification of diseases and related health problems / World Health Organization. Geneva: World Health Organization; 2004.

30. Fine JP, Gray RJ. A proportional hazards model for the subdistribution of a competing risk. J Am Stat Assoc. 1999;94(446):496-509.

31. StataCorp. Stata Statistical Software: Release 15. College Station, TX: StataCorp LLC. 2017.

32. Gjertsen F, Bruzzone $S$, Griffiths CE. Burden of suicide presented as one of the leading causes of death: uncover facts or misrepresent statistics? I Glob Health. 2019;9(1):010401

33. Cavanagh JT, Carson AJ, Sharpe M, Lawrie SM. Psychological autopsy studies of suicide: a systematic review. Psychol Med. 2003;33(3):395-405

34. Ilgen MA, Bohnert AS, Ganoczy D, Bair MJ, McCarthy JF, Blow FC. Opioid dose and risk of suicide. Pain. 2016;157(5):1079-84.

35. Austin AE, Proescholdbell SK, Creppage KE, Asbun A. Characteristics of selfinflicted drug overdose deaths in North Carolina. Drug Alcohol Depend. 2017:181:44-9.

36. Samples H, Stuart EA, Olfson M. Opioid use and misuse and suicidal behaviors in a nationally representative sample of US adults. Am J Epidemiol. 2019;188(7):1245-53.

37. Schneider B. Substance use disorders and risk for completed suicide. Arch Suicide Res. 2009;13(4):303-16.

38. Pfeifer P, Bartsch C, Hemmer A, Reisch T. Acute and chronic alcohol use correlated with methods of suicide in a Swiss national sample. Drug Alcohol Depend. 2017:178:75-9.

39. Kolves K, Draper BM, Snowdon J, De Leo D. Alcohol-use disorders and suicide: results from a psychological autopsy study in Australia. Alcohol. 2017;64:29-35

40. Park CHK, Yoo SH, Lee J, Cho SJ, Shin MS, Kim EY, et al. Impact of acute alcohol consumption on lethality of suicide methods. Compr Psychiatry. 2017;75:27-34.

41. van Ours JC, Williams J, Fergusson D, Horwood LJ. Cannabis use and suicidal ideation. J Health Econ. 2013;32(3):524-37.

42. Borges G, Benjet C, Orozco R, Medina-Mora M-E, Menendez D. Alcohol, cannabis and other drugs and subsequent suicide ideation and attempt among young Mexicans. J Psychiatr Res. 2017;91:74-82.

43. Hurd YL, Yoon M, Manini AF, Hernandez S, Olmedo R, Ostman M, et al. Early phase in the development of Cannabidiol as a treatment for addiction: opioid relapse takes initial center stage. Neurotherapeutics. 2015;12(4):807-15.

44. Lac A, Luk JW. Testing the Amotivational syndrome: marijuana use longitudinally predicts lower self-efficacy even after controlling for demographics, personality, and alcohol and cigarette use. Prev Sci. 2018:19(2):117-26.

45. Hesse M. Integrated psychological treatment for substance use and comorbid anxiety or depression vs. treatment for substance use alone. A systematic review of the published literature. BMC Psychiatry. 2009:9.

46. Delgadillo J, Gore S, Ali S, Ekers D, Gilbody S, Gilchrist G, et al. Feasibility randomized controlled trial of cognitive and behavioral interventions for depression symptoms in patients accessing drug and alcohol treatment. J Subst Abus Treat. 2015;55:6-14.

47. Watkins KE, Hunter SB, Hepner KA, Paddock SM, de la Cruz E, Zhou AJ, et al. An effectiveness trial of group cognitive behavioral therapy for patients with persistent depressive symptoms in substance abuse treatment. Arch Gen Psychiat. 2011:68(6):577-84.

48. Baker AL, Kavanagh DJ, Kay-Lambkin FJ, Hunt SA, Lewin TJ, Carr VJ, et al. Randomized controlled trial of MICBT for co-existing alcohol misuse and depression: outcomes to 36-months. J Subst Abus Treat. 2014;46(3):281-90.
49. Assefa MT, Ford JH, Osborne E, Mcllvaine A, King A, Campbell K, et al. Implementing integrated services in routine behavioral health care: primary outcomes from a cluster randomized controlled trial. BMC Health Serv Res. 2019;19(1):749.

50. Nunes EV, Levin FR. Treatment of depression in patients with alcohol or other drug dependence - a meta-analysis. JAMA. 2004;291(15):1887-96.

51. Hesse M. Achieving abstinence by treating depression in the presence of substance-use disorders. Addict Behav. 2004;29(6):1137-41.

52. Agabio R, Trogu E, Pani PP. Antidepressants for the treatment of people with co-occurring depression and alcohol dependence. Cochrane Database Syst Rev. 2018:4:CD008581.

53. Kandel DB, Hu MC, Griesler P, Wall M. Increases from 2002 to 2015 in prescription opioid overdose deaths in combination with other substances. Drug Alcohol Depend. 2017;178:501-11.

54. Turner BJ, Liang YY. Drug overdose in a retrospective cohort with noncancer pain treated with opioids, antidepressants, and/or sedativehypnotics: interactions with mental health disorders. J Gen Intern Med. 2015;30(8):1081-96.

55. Delgadillo J, Bohnke JR, Hughes E, Gilbody S. Disentangling psychopathology, substance use and dependence: a factor analysis. BMC Psychiatry. 2016;16:281.

56. Hesse M, Guldager S, Linneberg IH. Convergent validity of MCMI-III clinical syndrome scales. Brit J Clin Psychol. 2012;51:172-84.

57. Thylstrup B, Bloomfield K, Hesse M. Incremental predictive validity of the addiction severity index psychiatric composite score in a consecutive cohort of patients in residential treatment for drug use disorders. Addict Behav. 2018;76:201-7.

58. Rockett IRH, Caine ED, Connery HS, D'Onofrio G, Gunnell DJ, Miller TR, et al. Discerning suicide in drug intoxication deaths: Paucity and primacy of suicide notes and psychiatric history. PloS One. 2018;13(1):e0190200

59. Tollefsen IM, Hem E, Ekeberg O. The reliability of suicide statistics: a systematic review. BMC Psychiatry. 2012;12:9.

\section{Publisher's Note}

Springer Nature remains neutral with regard to jurisdictional claims in published maps and institutional affiliations.

Ready to submit your research? Choose BMC and benefit from

- fast, convenient online submission

- thorough peer review by experienced researchers in your field

- rapid publication on acceptance

- support for research data, including large and complex data types

- gold Open Access which fosters wider collaboration and increased citations

- maximum visibility for your research: over $100 \mathrm{M}$ website views per year

At BMC, research is always in progress.

Learn more biomedcentral.com/submissions 